\title{
Análise do discurso da imprensa sobre rebeliões de jovens infratores em regime de privação de liberdade
}

\author{
Discourse analysis on press coverage of riots \\ by juvenile law offenders in correctional facilities
}

Kathie N jaine 1

M aria Cecília de Souza M inayo 2

1 Centro Latino-Americano de Estudos de Violência e Saúde Jorge Carelli, Fundação Oswaldo Cruz. Av. Brasil 4036, sala 700, Manguinhos, 21040-361, Rio de Janeiro RJ. Doutoranda da Escola Nacional de Saúde Pública kathie@claves.fiocruz.br 2 Claves, Fiocruz.

Fórum Mundial de Ciências

Sociais e Medicina

\begin{abstract}
This study presents a qualitative analysis of information produced by the press on riots and escapes by juvenile offenders under correctional custody in Rio de Janeiro. The objective was to identify how the printed media portrays these social subjects to society. The method used to unveil the messages was discourse analysis, which includes various theoretical and technical approaches but was used here as proposed by N orman Fairclough. The study on three newspapers covering inmate riots was justified by the frequency and way by which the media approached the theme. The conclusions point to the media's role in bolstering a negative and incriminatory view of adolescents under correctional custody which has the potential to spawn further violent measures against this group. Very rarely does the coverage reveal the social or institutional issues or pedagogical insufficiencies permeating such events.
\end{abstract}

Key words Discourse analysis, Printed media and violence, Juvenile law offenders, Growth and development, Risk factors
Resumo Este trabalho apresenta uma análise qualitativa da informação produzida pela imprensa escrita sobre as rebeliões e fugas de adolescentes em conflito com a lei, no Rio de Janeiro. Seu objetivo é identificar como esse sujeito social éapresentado pela mídia escrita à soci edade. 0 método utilizado para 0 aprofundamento das mensagens éa análise de discurso, que embora compreenda várias vertentes teóricas e técnicas, aqui é abordado dentro da proposta de Norman Fairclough. 0 estudo da abordagem de três jornais sobre rebeliões de internos infratores se justifica em função da freqüência e da forma como a mídia tem destacado o tema. As conclusões apontam para o papel da mídia no fortalecimento da visão negativa e incriminadora dos jovens, que pode contribuir com ações mais violentas contra esse grupo. M uito raramente revela as questões sociais, institucionais e de inadequação pedagógica que permeiam tais eventos.

Palavras-chave Análise de discurso, M ídia impressa eviolência, Adolescente infrator, Crescimento e desenvolvimento, Fatores de risco. 


\section{Introdução}

Nunca é demais repetir que há várias maneiras de sofrer e de morrer dentro das páginas e hierarquias editoriais dos jornais. Sujeito sem voz, ou voz assujeitada à voz-leitora dos jornais, esse éo mecanismo que caracteriza a moderna narrativa jornalística (Fausto Neto, 1999).

O Programa de Saúde do Adolescente, da Divisão de Promoção e Proteção de Saúde da O rganização Pan-Americana de Saúde, publicou recentemente um documento que relaciona uma série de questões que vêm afetando a saúde e o desenvolvimento de crianças e adolescentes, dentre eles a violência na mídia (M cAlister, 2000). A identificação de fatores culturais e ambientais que possam contribuir para a prevenção da violên cia situa os meios de comunicação como um campo de investigação importante, porém ainda pouco estudado no contexto latino-americano.

Neste estudo procuramos analisar a forma como a imprensa escrita veicula e trata a questão da infração juvenil, em situação específica de rebelião de adolescentes que, por estarem em conflito com a lei, se encontram cumprindo medida socioeducativa de privação de liberdade (ECA, 1990). 0 pressuposto teórico do trabalho é de que a realidade social não é um conjunto de dados objetivos, nem de fenômenos que em si mesmos possam ser classificados como bons ou maus. Essas categorias de valores com as quais classificamos os eventos (inclusive a infração e a delinqüência) são partes do processo social construído, dinâmica e dial eticamente, de forma articulada a al gumas esferas de referência: o contexto social onde se desenvolvem as condições materiais de existência; a cultura por meio da qual a experiência vivida encontra seu reconhecimento no meio social; e a linguagem, que permite elaborar, comunicar, compartilhar e interpretar os fenômenos da realidade.

Essa introdução é necessária, uma vez que buscamos a desnaturalização de fenômenos e de conceitos, como éo caso das idéias de "lei" e de "crime", que, como já lembrava Durkheim (1981), nos fundamentos da sociologia, são obras das sociedades que Ihes dão formas e especificidades culturais. Esse clássico autor analisa como, nos diferentes contextos sociais, os ritos de punição aplicada aos transgressores têm menos a intenção de castigar o delinqüente do que o da exemplaridade, reafirmando a lei.

Para atingir os objetivos a que nos propusemos, adotamos o marco referencial da aborda- gem qualitativa que considera o cerne do sentido do discurso: 0 universo de significados, motivos, aspirações, crenças, valores e atitudes, que estão ligados a espaços de relações e fenômenos que não podem ser reduzidos à operacionalização de variáveis (M inayo, 1994). Formam os eixos que fundamentaram a análise das notícias: a) uma discussão teórica sobre a mídia e, em particular, a mídia impressa; b) uma contextualização da situação atual do adolescente infrator em relação aos atos que cometem e à posição do Estatuto da Criança e do Adolescente (ECA) frente a essa problemática; c) uma problematização das técnicas de análise de discurso para a compreensão da mensagem da mídia impressa.

\section{Marco referencial sobre a mídia e o contexto dos jovens infratores}

A análise dos diversos fenômenos informacionais (Sodré, 1992; Champagne, 1997) tem em comum a concepção de que eles fazem parte de um sistema que se articula à lógica da vida social. E que, nas sociedades modernas, esses meios ocupam um lugar privilegiado de produção e reprodução do real, tornando-se poderosos "interferentes" na organização do espaço relacional (H obsbawn, 1995; Ramonet, 1996).

Seu objeto essencial de trabalho, queéo discurso, se nutre, portanto, da própria construção da hegemonia, mas também das correntes contra-hegemônicas (Gramsci, 1981). Pois, como reflete M artin-Barbero (2001), para se manter por meio da mídia, o poder tem de, permanentemente, dialogar com seus contrários e com os que, por serem do meio popular, a elite considera de mau gosto, despreza ou menospreza. Faz parte da legitimação do poder atuar na complexidade de opiniões e posturas frente ao real, buscando, no entanto, ressaltar sua visão de mundo. É por causa dessas estratégias de concessão às diferenças articuladas à imposição de uma forma dominante de ol har o mundo, que os meios de comunicação acabam por ter forte influência cultural. I sso quer dizer que a mídia não cria preconceitos, julgamentos ou verdades, mas absorve o imaginário social, revestindo-o de uma roupagem especial, tecnicamente sofisticada e específica para agradar aos mais diferentes segmentos sociais e aos mais variados gostos.

No entanto, é preciso ressaltar que a mídia faz parte da dinâmica social, mas, agindo essencialmente no nível da ideologia, possui um grau 
de autonomia funcional. Essa especificidade é muito forte em momentos históricos como o nosso, que por sua vez se diferencia de outros tempos e espaços onde as formas de socialização predominantes eram orais e presenciais. Hoje, portanto, as diferentes formas de comunicação escritas, por imagens ou multimídias, provocam mudanças essenciais no campo das relações familiares, no papel de instituições como a escola e na reelaboração das duas categorias mais cruciais do pensamento humano: tempo e espaço. Ramonet (1996), diretor do Le M onde Diplomatique, se refere a esse papel incontestável da mídia, a que muitos denominam quarto poder, dizendo que "a comunicação se tornou a locomotiva do século XXI pela grande transformação tecnológica ocorrida". E H obsbawn (1995) denomina a mídia: "um grande ator social (...) poderoso contrapeso aos segredos dos governos".

Resumindo as estratégias de ação da imprensa e o papel fundamental que desempenha neste momento histórico, Oriol (2001) define sua atuação em três frentes simultâneas: a) a de controle que se refere à sua articulação com as classes e os val ores dominantes, cumprindo um papel de mediatização sociocultural; b) a de acomodação, cuja característica está voltada, mormente, para a construç̧ão da legitimação: segundo a educação, a idade, o sexo, a profissão, as pautas subculturais, a dinâmica das relações face a face e o contexto em que se dê, uma mesma mensagem dos meios de comunicação terá influências distintas uma vez que ela será decodificada e reinterpretada por quem a recebe; e por fim, c) há a atuação na informação propriamente dita, geralmente respondendo a indagações das classes médias eruditas que exigem matérias mais abrangentes, aprofundadas e críticas sobre os fatos e relações sociais. Esse último nível, o mais precariamente assumido, é o que aparece, ideologicamente, como a real função dos meios de comunicação.

0 papel da mídia impressa se realiza em dois planos: um que procura narrar as notícias do dia, procurando cumprir sua função informativa; outro, no qual se configura e expressa um sistema de valores, associado ao lugar do jornal como sujeito da enunciação. No entanto, como destaca Rebelo (2000), essa não é uma narrativa qualquer, é a narrativa do jornal, não mais se restringindo sobre "aquilo de que se fala", mas prevalecendo no plano do discurso, "de quemodo se fala" e"por que sefala". Os dois planos tornam o jornal socialmente reconhecido pelos leitores, o que inclui, obviamente também, o re conhecimento do estilo e do perfil do jornalista. Essa atividade da informação escrita apresenta diferenças em relação à mídia fal ada, porque, por ser menos fragmentária e possuir uma temporalidade maior, produz efeitos de agendamento de temas publicamente importantes mais significativos (Wolf, 2001).

A reflexão aqui resumida conforma o quadro referencial que será utilizado para a análise do tema em debate. Na última década, a mídia, sobretudo a imprensa escrita, tem focalizado, com bastante freqüência, a situação da infância e adolescência brasileira. Certamente isso se deve aos recentes avanços dos direitos desse grupo específico, respaldados pelo esforço de vários atores sociais para a conscientização da sociedadea respeito do Estatuto da Criança e do Adolescente (ECA), que tem força de lei. 0 tema do adolescente infrator também ganhou destaque entre as notícias das tragédias sociais das grandes regiões metropolitanas, tanto na mídia impressa como na televisionada, evidenciando o foco que a sociedade nacional, a partir dos anos 80 (que configuram o início do processo de democratização pós-ditadura militar), passou a dar à problemática da violência social.

A década de 1980, na verdade, marca uma inflexão no aumento da mortalidade por violência e da criminalidade urbana, em todas as faixas de idade e especialmente entre os jovens. Entre 1980 e 1988 a proporção de crianças e adolescentes de 10 a 14 anos mortas violentamente no Rio de Janeiro cresceu em $79,5 \%$. Na faixa dos 15 aos 19 anos, o crescimento foi da ordem de $45,3 \%$, sendo a principal causa de óbito neste grupo etário (Souza; Assis \& Silva, 1997). Houve também grande incremento no número de jovens envolvidos em atos infracionais. Estudos recentes de Assis (1999) e Cruz N eto et al. (1999) têm demonstrado que o crescimento dos números e das taxas de delitos se deu, no caso do Rio de Janeiro, principalmente pela inserção de crianças e adolescentes no mercado varejista do tráfico de drogas, enquanto, no país, a face mais exposta da delinqüência juvenil é representada pelos roubos, furtose, de forma pouco significativa, por homicídios ou tentativas de homicídio. Às transgressões desse grupo social, a imprensa tende a reagir, qualificando-os como "pequenos predadores", "pivetes", "futuros bandidos" (Volpi, 1997).

O ECA, no artigo 104, cujo texto éfreqüentemente criticado por muitos jornalistas e, de forma muito severa, por alguns segmentos da 
sociedade, prevê que menores de 18 anos de idade são penalmente inimputáveis. Constatada a prática de atos infracionais, a eles poderão ser aplicadas medidas soci oeducativas tais como advertência, obrigação de reparar o dano, prestação de serviços à comunidade, liberdade assistida, inserção em regime de semiliberdade, internação em estabelecimento educacional (art. 112) e outras, voltadas para inserção na família, na escola e na comunidade. A internação só deve ocorrer, segundo o ECA, em algumas situações em que seus atos configuram grave violência contra a pessoa. 0 tempo de cumprimento das medidas de internação é variável, não podendo ultrapassar a três anos.

Embora as medidas preconizadas pelo Estatuto estejam sendo implementadas pelo poder judiciário, houve pouca modificação no que se refere aos equipamentos sociais que dariam suporte às ações determinadas pelo Estatuto. Agravando esse fato, encontra-se a frágil atuação de muitos Conselhos de D efesa e Tutelares, instâncias de proteção também previstas pelo ECA. Assim, o estado real de precariedade do cumprimento das medidas socioeducativas contribui para o quadro atual de questionamento, discriminação e, por vezes, de rejeição por parte de vários segmentos da sociedade, às propostas constitucionais de direitos das crianças e dos adolescentes.

No caso da imprensa, há duas tendências mais evidentes em relação à infração juvenil, tal como tratada pelo ECA. U ma afirma a incapacidade do Estatuto para resolver o problema da criminalidade. A segunda busca ressaltar a complexa realidade da infância e da juventude brasileiras, sobretudo os problemas dos segmentos empobrecidos e miseráveis. A primeira tem muito mais força e apelo. Essa postura não foge ao que foi já observado teoricamente neste artigo, ou seja, a imprensa tende a repercutir as idéias dominantes da sociedade. Por exemplo, atual mente tramitam no Congresso $\mathrm{Nacional}$ 14 projetos propondo alterar a Constituição Federal para reduzir a maioridade penal de 18 para 16 anos, fato que reflete o quanto os comportamentos de tran sgressão dos jovens incomodam - mormente no caso dos das classes populares - e ao mesmo tempo, o quanto está arraigada na sociedade a idéia de que mais repressão diminui a violência.

É importante assinalar também que a cobertura jornalística da violência contra crianças e adolescentes está muito mais centrada na de linqüência que na vitimação. Por exemplo, o nú- mero de notícias divulgadas sobre os assassinatos cometidos contra esse grupo é muito pe queno quando comparado com as taxas de homicídios. Nos noticiários, os casos que me recem menos destaque são os crimes cometidos contra crianças e adolescentes das camadas populares. É como se sua vida valessemenos, ou se, ao morrerem, a perda social fosse menor (M N M M R, I base, NEV/U SP, 1991). Por outro lado, os hol ofotes da imprensa se colocam sobre os crimes cometidos pel os jovens infratores pobres. Isso reafirma o pensamento de Champagne (1997) segundo o qual a atenção da mídia, do ponto de vista da imputação do crime, são as populações socialmente marginalizadas. Trata-se de uma relação de poder desigual, pois a construção discursiva dos acontecimentos que as atinge fica total mente nas mãos dos jornalistas, geralmente de classe média e distanciados espacial e cultural mente da realidade que constitui seu modo e suas condições de vida.

Portanto, neste artigo existe a pressuposição de que a ação da mídia, frenteà questão do adolescente infrator, tende a forjar uma imagem negativa e preconceituosa, contribuindo para ações violentas que atentam contra a saúde física e psicológica desses jovens. E que, apenas excepcionalmente, (des)constrói os estereótipos e alerta para a violação dos direitos desse grupo, chamando para uma reflexão mais crítica sobre a complexidade do contexto em que os atos de transgressão ocorrem.

\section{Breve histórico do atendimento ao adolescente em conflito com a lei no Rio de Janeiro}

Com a criação do Departamento de Ações Socioeducativas (D egase) em 1994, como parte da Secretaria de Estado de Justiça, para cumprir as atribuições da antiga Fundação Nacional do Bem-Estar do M enor (Funabem), o Rio de Janeiro efetivou, tardiamente, a descentralização da gestão do sistema de atendimento para jovens que cometem atos infracionais, do nível federal para o estadual. Essa transição previa o reordenamento institucional, visando à implementação de programas socioeducativos dentro dos princípios do ECA. No final do mesmo ano, três unidades de internamento foram incendiadas e nos escombros, encontrados instrumentos de tortura. Esse fato levou à demissão de todos os funcionários federais que continuavam trabalhando no órgão já descen- 
tralizado. Os novos funcionários do Degase assumiram sem nenhuma capacitação e nas condições em que se encontravam os prédios após o incêndio. Vários episódios da mesma natureza se repetiram, alguns tendo como conseqüência a morte de adolescentes. Diferentes diretores também passaram pelo Degase, alguns propondo mudanças profundas no sistema. Poucas se efetivaram e a maioria sofreu fortes resistências por parte de agentes defensores de ações estritamente repressivas para o "controle" dos jovens (Claves, 1999). À sombra dessas tentativas, portanto, permanecia viva e vigorosa a pesada cultura institucional de mais de um século de repressão (Pilotti \& Rizzini, 1995) aqui apresentada nos discursos da imprensa.

\section{Material e método}

Neste artigo estão anal isadas 38 matérias jornalísticas referentes a rebeliões e fugas de jovens abrigados em instituições destinadas ao cumprimento de medida socioeducativa de privação de liberdade, (ECA, art. 112). Essas notícias foram extraídas de quatro volumes de clippings, elaborados pelo Claves sob o título "Jovens envolvidos em atos infracionais", selecionadas durante um ano - de setembro de 1997 a agosto de 1998 de três jornais de grande circulação no Estado do Rio de Janeiro: 0 Dia com 12 matérias; 0 Globo com 15 e o Jornal do Brasil com 11. Esses periódicos alcançam diferentes públicos e estratos sociais.

No trabalho empírico e operacional sobre as mensagens veiculadas, buscamos diferenciar os seguintes aspectos: a) a contextualização das instituições para internamento de adolescentes infratores no período em análise, no qual ocorreram as oito rebeliões; b) as diferentes representações dos atores envolvidos nas rebeliões e as formas de abordagem pelos jornais: 0 Dia; O Globo; e o Jornal do Brasil; (c) as idéias mais recorrentes atribuídas pelos três, como motivos para as rebeliões e as interpretações sobre as conseqüências dessas revoltas.

Para a compreensão das notícias veiculadas utilizou-se o método de análise de discurso referido por Fairclough (2001) que trabal ha com a abordagem lingüística de acordo com Bakhtin (1986); com as idéias de interdiscurso de Pêcheux (1990); com as categorias de hegemonia e contra-hegemonia de Gramsci (1981); e com os conceitos de prática e de ordem discursiva na mesma linha de Foucault (1996). Fairclough, balizado nos referidos autores, discute não só a compreensão dos textos, mas a forma de analisá-los e interpretá-los, como um modo particular do uso da linguagem e de outras expressões simbólicas, refletindo e representando, constituindo e construindo relações sociais. Considera o discurso, simultaneamente, texto, interação e prática social. No caso em pauta, das matérias sobre as rebeliões dos adolescentes infratores em privação de liberdade, essa tridimensionalidade dos efeitos do discurso nos jornais significaria, de acordo com sua ótica, que esses periódicos posicionam e diferenciam essas pessoas no mundo em que vivem; interagem com as idéias da sociedade sobre o tema; e moldam a natureza de uma prática discursiva que reforça e por vezes questiona a prática social.

\section{Resultados}

As enunciações jornalísticas se diversificam em vários gêneros discursivos. Assim, podemos denominar os textos analisados como sendo do gênero notícia, ainda que eles possam conter outros gêneros na sua interdiscursividade. As 38 matérias dos três jornais trataram de oito rebeliões, com fugas de 329 jovens e as conseqüências advindas desses eventos. Todos os envolvidos foram adolescentes do sexo masculino, que constituem, no Rio de Janeiro, $95 \%$ da população internada nas instituições para infratores. Foram mortos dois garotos: um em conseqüência dos confrontos com policiais dentro da instituição e outro fora dela, quando foi liberado para ir para casa. Entre os rebelados, 80 saíram feridos. Cinco funcionários das instituiç̃es e um número impreciso de policiais seferiram nesses confrontos, embora a mai oria tenha sofrido lesões de pouca gravidade.

\section{D iferenciações de abordagens entre os três jornais}

Dos jornais analisados, o Jornal do Brasil e 0 Globo são destinados aos estratos médios e altos da população, enquanto 0 Dia se dirige aos segmentos médios mais bai xos e populares. Portanto, esses destinatários fazem parte das condições de produ ção do discurso desses veículos. Eliseo Verón (1978) faz importante distinção nesse sentido: os periódicos que atingem as classes mais altas as nomeiam como tal, ou seja, elas estão refletidas na própria topografia do 
discurso, como, por exemplo, na estrutura de se ções e de subseções. Nos periódicos populares o discurso não leva em conta a constituição dessa classe, embora eventos como os das rebeliões, aqui analisados, constituam parte da vida dessas camadas da população do Rio de Janeiro.

\section{Jornal O Dia}

Com base nas 12 matérias jornalísticas analisadas, verifica-se que a cobertura desse jornal ofereceu um tratamento mais digno aos adolescentes que cometeram atos infracionais, contextualizando suas condições de vida e saúde e freqüentemente dando-Ihes voz. Todas as reportagens foram veiculadas na seção Polícia.

0 Dia, no conjunto das matérias, dá ênfase aos seguintes temas: à falência e à má administração do sistema que atende aos jovens infratores; às fugas como conseqüência da saturação, pelo excesso de pessoas e pela ausência de um projeto pedagógico das instituições de internamento; às explicações dos próprios adolescentes sobre as principais causas dos motins: existência e freqüência de espancamentos e maus-tratos aplicados pelos monitores das instituições, condições muito precárias para o seu desenvolvimento nos estabelecimentos assim como a falta de acompanhamento institucional de sua situação e necessidades pessoais.

Esse jornal ouviu e veiculou também a fala do "responsável legal pelo interno", o Governo do Estado, que admitiu o problema da superlotação como causador das rebeliões, mas se restringiu, na análise do problema, a essa unicausalidade, reduzindo a idéia de uma política de atendimento à questão da falta de espaço físico. A mesma autoridade referiu-se, também nas reportagens, a promessas de melhorar as condições dos estabelecimentos e descentralizar as internações, criando novos espaços para cumprimento dessa medida prevista no ECA. Uma das falas veiculadas foi a do responsável pelo órgão da justiça, sob cuja tutela estão os jovens privados de liberdade: em breve o Rio poderá orguIhar-se de ter um sistema socioeducativo de adolescentes infratores que pode não ser o ideal, mas será aquele que mais se aproximará das altas finalidades previstas na legislação vigente ( N ota oficial do Governo do Estado, 0 Dia, 3/12/97). Como podemos constatar, por produzir um diagnóstico simplista do problema, a referida nota passa aos leitores a proposta de uma solução unidimensional, a que a matéria apenas se refere.
No final do ano de 1997, cerca de 150 adolescentes foram transferidos para um presídio de adultos em função de uma rebelião na Escola João Luiz Alves. Frente ao fato, 0 Dia se posicionou fortemente contra, invocando várias vezes a autoridade do ECA. "M enores infratores vão parar em presídio" (8/12/97), denunciava o jornal, citando o artigo 185 do Estatuto. Esse artigo proíbe terminantemente que se mantenham menores de 18 anos em prisão.

Em matéria, de 1/4/98, sob o título "Assim o Estado trata o menor", evocando o artigo 123 do ECA, onde se lê que a internação deve ser cumprida em entidade exclusiva para adolescentes, distinta das destinadas a abrigo, devendo haver rigorosa separação por critérios de idade, compleição física e gravidade da infração de cada um deles, esse jornal denunciou que os adolescentes transferidos para uma prisão estavam em lugar insalubre, convivendo com vazamento de água, lixo e pornografia. 0 foco principal de 0 Dia, na cobertura das notícias referentes a adolescentes em conflito com a lei, no período dejaneiro a agosto de 1998, foram as condições "ilegais" e de total negligência e abandono em que os adolescentes transferidos se encontravam no presídio Moniz Sodré.

O Dia foi o periódico que se destacou pela posição mais crítica e aprofundada na cobertura das rebeliões, ressaltando a subjetividade dos adolescentes e ouvindo-os na construção das notícias que lhes diziam respeito; denunciando a negligência do Estado, os maus-tratos e torturas cometidas por funcionários; e informando sobre o ECA e sua importância para a cidadania. No entanto, nele também, a expressão ainda mais utilizada para se referir aos adolescentes foi "menor". Essa adjetivação-substantivada que vem sendo usada desde os tempos de absoluto desprezo do Estado - materializado no Código de Menores - pelos meninos e adolescentes pobres, abandonados, vivendo nas ruas ou autores de infrações, continua a marcar a linguagem de classe de todos os meios de comunicação social do país. Tratar um adolescente como "menor" significa negar a história dele como pessoa e subsumir o "sujeito de direitos" proclamado no ECA, que a sociedade adultocêntrica teima em não reconhecer. Isso pode ser verificado no quadro resumo das denominações utilizadas nas matérias de todos os jornais. Os outros apel ativos são geralmente também depreciativos, contendo uma carga de menosprezo e humilhação ao sofrimento vivido por esses meninos. 


\section{Jornal O Globo}

Das 15 matérias de 0 Globo, todas foram veiculadas na página Rio, pois como acontece com todos os periódicos dirigidos à elite, neste também não existe uma seção Policial. No entanto, 0 tratamento dispensado aos adolescentes em rebelião esteve sempre referido à sua situação como delinqüentes e nomeados, respectivamente, como "menores infratores" e "internos". Esses adjetivos que os substantivaram foram colocados tanto nos textos dos repórteres como nas citações de al gumas autoridades responsáveis pela área da infância e da juventude. As matérias, em sua maioria, deram ênfase ao caráter de periculosidade, incontrolável e agressivo dos meninos.

A periculosi dade que lhes é atribuída obscurece qualquer reconhecimento de sua subjetividade, emotividade, historicidade e o fato de serem meninos em fase de crescimento e desenvolvimento. Em nenhuma matéria se falou de suas famílias, como se esses jovens compusessem um grupo alienado, sem raízes, sem relações primárias, sem sentimentos e afetos, a não ser a agressividade, o ódio ea raiva que os tornam anti-sociais. Com o olhar da sociedade "bem", as matérias projetam a idéia de que eles geram uma desordem social incontrolável e um caos social irremediável, em confronto com um poder público fraco, leniente, não suficientemente repressivo, enfatizando o esfacelamento da lei e da justiça. N essas coberturas, 0 Globo em nenhum momento fez menção ao ECA, como se a imprensa ainda tivesse como referência para a construção das informações, 0 antigo Código de M enores. M esmo quando, raramente, as reportagens se referiram à negação e à violação dos direitos desses jovens, os termos usados foram tão generalizantes que nada acrescentaram à caracterização de sua vida, de sua história e de sua situação.

As informações veiculadas em 0 Globo dão ênfase às "quantidades", ou seja, à magnitude das tragédias: o número de rebelados, quantos fugiram, quantos foram recapturados, quantos se feriram, imitando a mesma estrutura das notícias sobre rebeliões em prisões para adultos. A idéia colocada no ECA, "de privação de liberdade" como medida socioeducativa é substituída, conotativamente, pela de encarceramento de criminosos. Essa equiparação do adolescente ao adulto, no que concerne ao nível de responsabilização pelos atos que produz, vem servindo de apoio (com a contribuição explícita ou im- plícita da imprensa) para aqueles que defendem o rebaixamento da maioridade penal de 18 para 16 anos ou menos. Demonstra também a pouca, fraca e pobre incorporação, pelos jornalistas, da nova visão de cidadania trazida peIo ECA, até mesmo no que o texto do Estatuto permite de severidade no tratamento das infrações cometidas por adolescentes. A idéia de agressividade também foi tratada de forma impessoal, generalizante e descontextualizada, conotando "maldade inata". Por todas as constatações acima, concluímos que 0 Globo tem um tom muito mais incriminador que $0 \mathrm{Dia}$.

No entanto, assim como em todo o veículo de comunicação, esse periódico divulga algumas informações importantes. Considera, em algumas matérias, a violência sofrida, ao mencionar o número dos adolescentes feridos durante os eventos, bem como a gravidade dos ferimentos, embora essa informação possa propiciar várias leituras. Por exemplo, poderia estar sugerindo que as lesões são frutos do revide e da repressão necessários para conter esses meninos incontroláveis. M as poderia também ser reinterpretada, pelo leitor, como símbolo da violência de que adolescentes, em condições sociais de risco, são vítimas a propósito de ressocializá-los. Igualmente, as matérias se referem às rebeliões como conflitos oriundos da falta de infra-estrutura dos "presídios" (termo usado pelo jornal para se referir às instituições de cumprimento de medidas socioeducativas) por causa da superlotação e das queixas de maus-tratos verbalizadas com palavras e gestos de revolta pelos "menores infratores".

\section{Jornal do Brasil}

Nas 11 notícias do Jornal do Brasil sobre as rebeliões dos jovens infratores, em postura muito semelhante à de 0 Globo, os adolescentes são tratados preferencialmente como "menores", "meninos" e "internos". Da mesma forma que esse último, o Jornal do Brasil não tem a seção sobre criminalidade, e todas as notícias sobre 0 assunto foram publicadas na página Cidade.

Deforma menos discriminatória que 0 Globo, mas menos crítica que 0 Dia, o Jornal do Brasil ressaltou nas reportagens a violência institucional da qual os adolescentes são vítimas: a superlotação; os maus-tratos cometidos contra eles por parte dos agentes educacionais; o fato de um adolescente durante uma rebelião ter tido um traumatismo craniano; as práticas de tortura; a falta de higiene dos locais; o fato de 
que os adolescentes, após a rebelião, terem ficado sem banho e vários dias com a mesma roupa no corpo; a inexistência de atividades de formação, como cursos profissionalizantes; e a precariedade de funcionamento dos poucos projetos que ainda restavam nos internatos. Ao apontar esses problemas, porém, o Jornal do Brasil, na forma como os apresentou, transmitiu, aos leitores, a idéia de que a negligência e a violência institucional são repostas ao comportamento "agressivo" e "predatório" dos próprios adolescentes.

O problema da superlotação, que levou os adolescentes a destruírem o presídio Moniz Sodré, ocasionando assim uma nova rebelião, foi o destaque em 1998. Frente a isso, o Jornal do Brasil tomou uma posição ambígua. De um lado, reforçou a imagem de "menores incontroláveis", "agressivos", "selvagens", destacando a destruição do presídio pelos adolescentes. De outro, apresentou depoimentos de al gumas autoridades do governo criticando o fato de os jovens estarem confinados e ociosos em verdadeiros "presídios". Porém, nas notícias, se limitou a relatar os acontecimentos de forma "objetiva" (!), e muitas vezes extremamente sintetizadas. Para exemplificar, quando, em 14 de abril de 1998, ocorreu a primeira rebelião no Presídio M oniz Sodré, no dia seguinte, o Jornal do Brasil fez uma matéria resumida de 11 linhas, com 0 título "Menores põem fogo em presídio". Na mesma data 0 Dia, em "A primeira rebelião do M oniz Sodré", e 0 Globo, em "Rio manda menores infratores para outros estados", publicaram reportagens de quase meia página cada, sendo queO Dia deu espaço para a fala das mães que denunciavam os maus-tratos contra seus filhos dentro dos presídios. Quase dois meses depois, o Jornal do Brasil noticiou, num pequeno texto, repercutindo o que saíra anteriormente nos outros veículos, que a situação no presídio continuava a mesma. Enquanto isso, 0 Dia publicava uma cobertura ampla sobre os adolescentes, as instituições e o ECA sob o título "Crime, castigo e tratamento" (7/6/98), metaforizando D ostoievski na descrição da situação em que se encontravam as instituições de atendimento aos infratores, naquele momento.

0 ECA foi raramente mencionado por esse jornal, e assim mesmo só na fala de autoridades do governo ou de entidades que atuam nessa área, evidenciando, da mesma forma que 0 Globo, uma barreira ideológica para perceber 0 sentido transformador desse instrumento legal para as crianças e os adolescentes. Talvez por não tomarem conhecimento do ECA, ambos os periódicos em nenhum momento apresentaram todas as possibilidades nele assinaladas para cumprimento de medidas socioeducativas, já mencionadas na introdução deste artigo.
É importante assinalar que esses periódicos, principalmente 0 Globo e Jornal do Brasil, freqüentemente iniciam os títulos de suas matérias com a denominação "menores". Ao não utilizarem 0 artigo definido ou indefinido no início da maioria dos títulos, seus autores reforçam o menosprezo, a idéia de não-sujeito, de grupo informe, ou seja, a estigmatização desses adolescentes pela mídia. Além disso, ao colocarem a palavra "menores" como sujeito indefinido das frases, os títulos enunciam, estrategicamente, a condição de oposição entre esses meninos e os adolescentes não-infratores, assinal ando a inferioridade dos primeiros, ao mesmo tempo em que não os distinguem nem como sujeitos reais.

\section{Quadro 1}

Denominações dos adolescentes em conflito com a lei nas matérias jornalísticas (setembro de 1997 a agosto de 1998)

\begin{tabular}{|c|c|c|}
\hline Jornais/Denominações & № & $\%$ \\
\hline \multicolumn{3}{|l|}{ O Dia } \\
\hline Menores & 53 & $42,4 \%$ \\
\hline Meninos & 32 & $25,6 \%$ \\
\hline Internos & 19 & $15,2 \%$ \\
\hline Adolescentes & 8 & $6,4 \%$ \\
\hline Infratores & 6 & $4,8 \%$ \\
\hline Fugitivos & 4 & $3,2 \%$ \\
\hline M eninos reincidentes & 2 & $1,6 \%$ \\
\hline Menino carente & 1 & $0,8 \%$ \\
\hline Total & 125 & \\
\hline \multicolumn{3}{|l|}{ O Globo } \\
\hline Menores infratores & 85 & $35,3 \%$ \\
\hline Menores & 81 & $33,8 \%$ \\
\hline Internos & 39 & $16,3 \%$ \\
\hline Adolescentes & 11 & $4,6 \%$ \\
\hline Adolescentes audaciosos & 9 & $3,8 \%$ \\
\hline Meninos & 8 & $3,3 \%$ \\
\hline Presos & 5 & $2,1 \%$ \\
\hline Jovens indefesos & 2 & $0,8 \%$ \\
\hline Total & 240 & \\
\hline \multicolumn{3}{|l|}{ Jornal do Brasil } \\
\hline Menores infratores & 69 & $39,6 \%$ \\
\hline Menores & 27 & $15,5 \%$ \\
\hline Internos & 23 & $13,3 \%$ \\
\hline Meninos & 13 & $7,5 \%$ \\
\hline Adolescentes audaciosos & 12 & $6,9 \%$ \\
\hline Adolescentes & 11 & $6,3 \%$ \\
\hline Presos & 8 & $4,6 \%$ \\
\hline Jovens rebelados & 7 & $4,0 \%$ \\
\hline Assassinos & 2 & $1,2 \%$ \\
\hline Batedor de carteira & 2 & $1,2 \%$ \\
\hline Total & 174 & \\
\hline
\end{tabular}


Quadro 2

Títulos das matérias jornalísticas sobre rebeliões (setembro de 1997 a agosto de 1998)

\begin{tabular}{|c|c|}
\hline Jornais/Matérias & Data \\
\hline $\begin{array}{l}\text { O Dia (12 matérias) Seção Polícia } \\
\text { Um ano fugindo da desordem } \\
\text { Menores infratores vão parar em presídio } \\
\text { Mais de } 100 \text { menores no M oniz Sodré } \\
\text { Menores ficam presos por mais de dois meses } \\
\text { Assim o Estado trata o menor } \\
\text { Um cruel campo de concentração } \\
\text { Menores infratores estão ilegalmente em presídio } \\
\text { A primeira rebelião do M oniz Sodré } \\
\text { Trezentos e sessenta menores incendeiam alojamento do Moniz Sodré } \\
\text { Crime, castigo e tratamento } \\
\text { O desespero que vira coragem } \\
\text { Menor infrator tenta fugir eé baleado }\end{array}$ & $\begin{array}{r}3 / 12 / 97 \\
8 / 12 / 97 \\
19 / 12 / 97 \\
20 / 12 / 97 \\
1 / 4 / 98 \\
2 / 4 / 98 \\
6 / 4 / 98 \\
14 / 4 / 98 \\
5 / 5 / 98 \\
7 / 6 / 98 \\
30 / 6 / 98 \\
18 / 8 / 98\end{array}$ \\
\hline $\begin{array}{l}\text { O Globo ( } 15 \text { matérias) Seção Rio } \\
\text { Estado quer dar indulto para menores infratores } \\
\text { Menores infratores dormem no chão do ginásio } \\
\text { Menor é morto a tiro durante rebelião } \\
\text { Trinta e quatro menores infratores fogem na Ilha } \\
\text { Menores quebram escola novamente } \\
\text { Menores vão para penitenciária } \\
\text { Menores infratores são postos para trabal har } \\
\text { Menores infratores vão para centros, mas não podem sair } \\
\text { Juiz vai pedir transferência imediata de menores } \\
\text { Menores infratores voltam a se rebelar } \\
\text { Justiça foi alertada para revolta de menores } \\
\text { Menores: comissão da OAB constata maus-tratos } \\
\text { Estado contratará } 150 \text { agentes educacionais } \\
\text { Doze menores fogem da Escola João Luiz Alves na Ilha } \\
\text { Menores infratores terão direito a visitas íntimas a partir dos } 14 \text { anos }\end{array}$ & $\begin{array}{r}20 / 9 / 97 \\
24 / 9 / 97 \\
15 / 11 / 97 \\
18 / 11 / 97 \\
3 / 12 / 97 \\
9 / 12 / 97 \\
11 / 12 / 97 \\
3 / 4 / 98 \\
10 / 4 / 98 \\
5 / 5 / 98 \\
12 / 5 / 98 \\
14 / 5 / 98 \\
15 / 5 / 98 \\
23 / 8 / 98 \\
30 / 8 / 98\end{array}$ \\
\hline $\begin{array}{l}\text { Jornal do Brasil ( } 11 \text { matérias) Seção Cidade } \\
\text { Menino morre em rebelião de menores } \\
\text { Morte gera luta por justiça } \\
\text { Mais } 15 \text { menores fogem em rebelião } \\
\text { Rebelião de menores deixa } 25 \text { feridos } \\
\text { Menores põem fogo em presídio } \\
\text { Menores destroem Instituto } \\
\text { Menores rebelados não têm para onde ir } \\
\text { Moniz Sodré continua com menores infratores } \\
\text { Promotor pede revisão da lei do menor } \\
\text { Crianças infratoras de até } 12 \text { anos terão abrigo } \\
\text { Revisão definirá visita íntima }\end{array}$ & $\begin{array}{r}13 / 11 / 97 \\
16 / 11 / 97 \\
18 / 11 / 97 \\
3 / 12 / 97 \\
15 / 4 / 98 \\
5 / 5 / 98 \\
12 / 5 / 98 \\
5 / 6 / 98 \\
18 / 8 / 98 \\
21 / 8 / 98 \\
28 / 8 / 98\end{array}$ \\
\hline
\end{tabular}

\section{Em que as matérias convergem?}

As rebeliões retratadas nos três jornais compõem dois importantes eixos interpretativos: 0 primeiro diz respeito à sua veiculação como sendo de caráter destruidor, devastador e incontrolável, enfatizado e justificado em vários títulos e nos corpos das notícias, testemunhando e legitimando a ação repressora e violenta contra eles. 0 enredo dessas informações foi nitidamente de viés policialesco.

Expressões como "baderna”, "motim", "confusão", "revolta", "tumulto" são recorrentes nos três jornais para narrar os acontecimentos. A elas é acrescentado, destacado e reiterado o termo "destruição" como a pal avra que mais representa os efeitos da rebelião, numa construção jornalística que sugere serem, tais eventos, fru- 
tos de atitudes agressivas sem propósito algum, "fúria dos menores", "selvageria". Tudo isso transmite e reforça a idéia de "periculosidade" e de "natureza essencialmente ruim", conotações emitidas em várias matérias. As tragédias anunciadas, outra idéia presente nas notícias sobre as rebeliões, igualmente apresentam uma noção de rotina perigosa e reprimida, ao mesmo tempo em que reafirmam fatalismo e idéia de imutabilidade da situação.

Nas narrativas dos confrontos entre policiais, monitores e adolescentes, observa-se uma equiparação indevida dos diferentes atores envolvidos na trama, como se todos tivessem a mesma força, as mesmas armas e as mesmas condições de reação. Por exemplo, os batal hões de choque da Polícia M ilitar, na maioria das ve zes, foram convocados para conter as rebeliões. Usaram armas de fogo, atiraram, utilizaram bombas de gás lacrimogêneo e de efeito moral. Em contraposição, os jovens os enfrentaram portando, basicamente, armas brancas, pedaços de madeira, pedras e outros objetos que encontraram pela frente. $M$ as as informaçõ̃es transmitidas aos leitores dos jornais tenderam a hiperbolizar a rebeldia e a agressividade dos rebelados.

As causas reais dos motins raramente foram questionadas e debatidas em profundidade, pois elas não configuram "um fato jornalístico": a forma sensacionalista com que foram tratados tais eventos e os contextos psicossociais e socioeconômicos em que esses jovens estão inseridos fora e dentro das instituições aparecem naturalizados. Estudos que partem da compre ensão da sua vida e da lógica de suas ações, como os de Assis (1999), mostram que esses adolescentes desenvolvem uma relação de ódio e rejeição com os internatos, onde as práticas cotidianas e as relações que estabelecem com os supostos educadores são, de fato, violentas, impessoais e orientadas mais para a repressão do que para a construção da cidadania.

Com relação às conseqüências das rebeliões, também os três periódicos enfatizaram muito mais os danos materiais causados pelos adolescentes e o clima de tensão gerado entre os funcionários e, muito menos, os efeitos de repressão e a cultura de violência que geraram as revoltas. M inuciosamente foi dada ênfase à destruição dos alojamentos e de outras dependências; à utilização de objetos transformados em armas; e ao medo dos moradores que vivem próximos aos institutos.

0 segundo eixo interpretativo para o qual a imprensa convergiu é o que trata das institui- ções de internamento. Embora menos presente, permaneceu, nas matérias, o mesmo diapasão da "desordem", da "anormalidade" e do pre conceito contra esses membros das "classes perigosas", e, por analogia, contra os locais que os abrigam. Os jornais expressaram essa conotação, em algumas matérias em que os termos centrais são as metáforas usadas para representar as instituições, tais como palcos de tragédia elocais de iminentes rompimentos da legalidade e da tranqüilidade social. O s internatos foram descritos como antros de violências contra os jovens e espaços onde não há limites para a violação dos seus direitos. Também foram nomeados hiperbolicamente como "barril de pólvora em estado de explosão", enunciando a incontrolabilidade, termos muito usados para a reprodução da mesma idéia de que tais adolescentes representam imenso perigo para a sociedade.

Por outro lado, embora denunciada pela negligência, maus-tratos e falta de infra-estrutu$\mathrm{ra}$, a perene lógica burocrática e punitiva das instituições de ressocialização não é retratada nem problematizada pela mídia, de um modo geral. A crítica, quando feita, refere-se a um tipo de instituição abstrata, composta por pessoas incompetentes para manter a ordem e assegurar a paz para a sociedade "bem". 0 projeto pedagógico que, pela sua total inconsistência transformadora, acaba por criar, recriar e reforçar os papéis de delinqüentes, não encontra espaço político-informacional. O u seja, aqui, como diria, Norman Fairclough (2001), a constituição discursiva da sociedade não emana de um livre jogo de idéias nas cabeças das pessoas, mas de uma prática social que está firmemente enraizada em estruturas sociais materiais, concretas, orientando-se para elas.

Sobre os atores ouvidos pela imprensa para a construção das notícias sobre as rebeliões dos infratores juvenis aparecem várias falas e protocolos discursivos, relatos alheios junto ao próprio discurso jornalístico. Assim como na hierarquia do espaço gráfico dado à notícia sobre essas rebeliões, essas falas também aparecem modeladas por uma hierarquização segundo uma ordem de importância que é dada por cada jornal aos atores envolvidos.

Em primeiro lugar aparecem os discursos das autoridades com representações institucionais e diretamente responsáveis pela área da infância e adolescência como: o da Promotoria Pública; o do Juizado da 2a Vara da Infância e Juventude do Rio de Janeiro; o da Secretaria de Justiça do Rio de Janeiro e Ministério da Justi- 
ça; o do Degase e dos funcionários das unidades de atendimento; e o dos assessores de imprensa dos órgãos públicos. Em segundo lugar, vem a fala de pessoas de entidades civis que militam na defesa dos direitos da criança e do adolescente. Em terceiro, destacam-se as opiniões das autoridades responsáveis pela segurança pública. Esse conjunto de atores, nas matérias, aparece falando diretamente com a imprensa, sendo, portanto, os principais responsáveis pela divulgação da política local de enfrentamento da delinqüência juvenil a partir do ECA. Seus pronunciamentos se dirigiram tanto no sentido de reafirmar a implementação do Estatuto, quanto no intuito de criticá-lo. Não podemos desconhecer que esses atores sociais configuram grupo forte de formadores de opinião sobre o tema em debate.

As vozes dos adolescentes raramente foram e são ouvidas e nunca suas razões são tratadas seriamente nas reportagens. Seu isolamento constitui um ato político de exclusão que reforça a negação de sua presença social. Da mesma forma, suas famílias, apenas em momentos de ocorrência de tragédias gravíssimas e fatais, foram e são ouvidas. Por exemplo, isso aconteceu por ocasião da morte de um adolescente dentro da instituição, alvejado pela arma de um policial com um tiro na cabeça, em novembro de 1997. Aí os jornal istas entrevistaram a mãe, pois o caso "transformou-se em fato jornalístico". Prevalecem, portanto, nessa "arena" discursiva, a voz do Estado, das fontes públicas de informação que tendem a ser impessoais, legalistas e reafirmadoras do status quo. Concluindo, na quase totalidade dos textos faltou a palavra dos sujeitos principais, restando-Ihes, apenas, a linguagem dos gestos de revolta.

É importante assinalar, no entanto, os fugidios instantes em que o muro da insensibilidade foi atravessado por notícias fragmentadas nos quais se fez menção à subjetividade e à forte mobilização emocional dos jovens. É o caso, por exemplo, de matérias sobre motins em vésperas de Natal, Ano Novo e Dia das M ães, datas em que, na nossa sociedade, as famílias, mesmo as mais pobres, se reúnem e se confraternizam. Assim a reportagem "Queria passar o natal em casa" do Jornal do Brasil, em 13/11/97 noticiou a história de um adolescente que já havia cumprido o período determinado de internação e que fugira durante a rebelião para passar a data com sua família. Em "M enores quebram escola novamente", o Globo, em 31/12/97, focalizou o clima de tristeza e solidão desses meninos, na data de celebração do Ano Novo. Em "M enores destroem instituto", o Jornal do Brasil, de 5/5/98, comentou uma rebelião ocorrida exatamente às vésperas do dia das $\mathrm{M}$ ães. $\mathrm{Na}$ mesma data, $\mathrm{O}$ Dia, em "Presídio destruído", repercutiu e referenciou o acontecimento citado pelo Jornal do Brasil, com uma reportagem em que se ressaltavam as expressões e sentimentos de frustração e solidão dos meninos, por estarem distantes da mãe, a figura familiar mais respeitada e preservada pelos adolescentes infratores, quando expressam suas emoções.

A morte de um jovem, em novembro de 1997, foi a mais grave violência ocorrida dentro dessas instituições, no período estudado. A conseqüência do ato fatal foi mostrada nos jornais por meio de narrativas que enfatizaram a Iuta quase solitária da mãe em luto. Ela tentava bravamente provar que o tiro que matou o menino veio da arma de um policial eque seu filho havia sido torturado antes de morrer. "M orte gera luta por justiça", assinal ou o Jornal do Brasil em 16/11/97. É de se notar que a dor e o sofrimento das famílias, danos emocionais raramente apontados nas notícias analisadas, são fartamente repercutidos quando ocorre al go, sobretudo casos fatais, em famílias de jovens dos estratos sociais mais el evados.

Outro momento em que constatamos abordagens mais cuidadosas e solidárias por parte dos jornalistas dos três periódicos foi quando narraram a cruel dade dos castigos infligidos aos adolescentes, após as rebeliões. Todos denunciaram a aplicação de castigos como: o de dormir no chão do ginásio sem colchão e sem cobertor (O Globo, 24/9/97); punições físicas (Jornal do Brasil, 11/12/97); e privação de atividades pedagógicas efísicas (O Dia, 7/6/98). A tendência dos jornais foi se manifestar contra esses castigos, repercutindo e apoiando os argumentos e denúncias das entidades que trabalham em defesa dos direitos da infância e da adolescência. Ao mostrar essa tensão existente entre a atitude re pressora das instituições de internação e as entidades que lutam para pôr fim a essa cultura de privação e punição, por alguns momentos, os três jornais propiciaram, de um certo modo, a politização do debate público sobre o tema.

\section{Conclusões: a marca do estigma e as possibilidades de superação}

Volpi (1997) destaca que as crianças e os adolescentes de classe média, com a promulgação 
do ECA, passaram a ter mais um instrumento a favor de seu desenvolvimento e do seu reconhecimento como sujeitos de direitos e destinatários de proteção integral. Porém, diferenciamse, claramente, das crianças e dos adolescentes das camadas populares e, de forma muito particular, dos pobres que cometem atos infracionais. Sob o olhar da saúde, esse último grupo é fortemente prejudicado em seu crescimento e desenvolvimento emocional, intelectual esocial.

A ideologia que os discrimina e os desconhece como sujeitos de direitos e os substantiva como "menores" se produz na sociedadee se re trata na imprensa por meio do estigma de marginalidade. A narrativa jornalística, em particular a de estilo policialesco, tem sido um dos setores responsáveis, frente à opinião pública, pela construção da imagem de crianças e os adolescentes associados a animais, como seres de natureza perversa, nocivos à sociedade, sujeitos sem recuperação ou desumanos, com agressividade incontrolada (Gomide, 1990). Como numa profecia auto-anunciada, na trajetória de sua vida institucional, a maioria dos adolescentes infratores em instituições de internamento acaba por assumir o futuro que a sociedade the impôs: segundo dados do relatório da avaliação do Degase realizado pelo Claves em 1999, 60\% dos atuais apenados do sistema penitenciário do Rio de Janeiro são oriundos das instituições de internamento de jovens infratores (Claves, 1999).

Nessa história, freqüentemente, as matérias jornalísticas acabam por ser um ingrediente poderoso a mais na construção da violência que sofrem os jovens, sobretudo pela carga de discriminação e preconceito que veiculam. É verdade, e aqui constatamos isso, não há homogeneidade no comportamento da mídia. Há diferenças entre os periódicos, e também no modo como cada jornalista se aproxima da questão. Mas, a elaboração deste estudo nos mostrou que a linha editorial dos jornais tem um peso maior do que a sensibilidade dos seus repórteres, pelo menos no que tange ao assunto aqui tratado. 0 Estatuto da Criança e do Adolescente, já completando 12 anos, não costuma fazer parte dos temas relevantes dos órgãos de informação.

É importante ressaltar que alguns jornalistas vêm se destacando por elaboração de textos claramente contrários à violência contra crianças e adolescentes. Pela profundidade e atuali- dade das matérias que produzem, têm merecido até mesmo prêmios no país e no exterior. Mas, de forma geral, notamos um desconhecimento muito grande dos instrumentos de direito da infância e da juventude configurados no ECA, por parte da maioria dos profissionais da imprensa.

U ma atividade em função da modificação desse status quo, merecendo ser sublinhada, é a que vem sendo desenvolvida pela Agência de Notícias dos Direitos da Infância (Andi). Essa entidade não-governamental atua junto à imprensa no país, no sentido de sensibilizar e oferecer pautas a favor da cidadania das crianças e dos adolescentes. Atuar a favor do ECA, hoje, é agir numa linha política de longo prazo na construção da cidadania no país, assim como é dar sua contribuição para uma sociedade mais "civilizada". Afirmamos isso a partir de vários estudos nos quais os autores mostram ( $M$ inayo \& Souza, 1999; Assis, 1999) que a violência, os maus-tratos e a falta de reconhecimento desses grupos sociais em crescimento e desenvolvimento contribuem para a ampliação da violência social em geral.

Hoje, a vigência do ECA éainda muito precária, mesmo depois de 12 anos de sua promulgação. Recente documento do Unicef denuncia que a maior parte dos princípios do Estatuto não atinge 14 milhões de crianças e jovens com menos de 18 anos no Brasil. Há um milhão de meninos e meninas entre sete e 14 anos fora da escola; 220 mil meninas com até 14 anos trabaIhando como empregadas domésticas; $45 \mathrm{mil}$ crianças vivendo em lixões; e 1,9 milhões de jovens analfabetos (Andi/IAS/Unesco, 2000). M ais problemática de todas as questões, no entanto, é a condição da criança e do adolescente em conflito com a lei. Há um movimento de grupos sociais politicamente poderosos trabalhando para redução da idade penal, mesmo sabendo da gritante contradição que significa 0 atendimento carcerário e repressor a eles prestado nos internatos. Trata-se de parte do processo de dominação sociopolítica que, na sua hegemonia, cerceia o desenvolvimento integral de crianças e adolescentes, em sua maioria, já discriminados desde o nascimento. Que este estudo seja uma gota d'água no oceano das necessidades de avanço da cidadania em nosso país, no caso presente, a favor da efetiva implantação do Estatuto da Criança e do Adolescente. 


\section{Referências bibliográficas}

Andi/IAS/Unesco 2000. Os jovens na mídia. Série M obilização Social. Edição Agência de Notícias dos Direitos da Infância, Instituto Ayrton Senna, Unesco, Brasília.

Assis SG 1999. Traçando caminhos numa sociedade menos violenta: a vida de jovens infratores e seus irmãos não infratores. Editora Fiocruz, Rio de Janeiro.

Bakhtin M 1986. Marxismo e filosofia da linguagem. Editora Hucitec, São Paulo.

Brasil 1990. Estatuto da Criança e do Adolescente. M inistério da Saúde, Brasília.

Campos AV 1984. 0 menor institucionalizado: um desafio para a sociedade. Editora Vozes, Petrópolis.

Champagne PA 1997. Visão mediática, pp. 63-79. In P Bordieu (org.). A miséria do mundo. Editora Vozes, Petrópolis.

Claves/Ensp/Fiocruz 1999. Avaliação do convênio U erj \& Degase: programa pró-adolescente: ações socioeducativas. Relatório de Pesquisa. Claves, Rio de Janeiro, 109pp.

Cruz Neto O \& et al. 1999. Adolescentes envolvidos pelo tráfico de drogas no Rio de Janeiro. Relatório Final de Pesquisa. Ensp, Rio de Janeiro, 160pp.

Durkheim É 1981. Suicídio. Editorial Presença, Lisboa.

ECA 1991. Estatuto da Criança e do Adolescente/M inistério da Saúde/M inistério da Criança. Brasília, 110pp.

Fairclough N 2001. Discurso e mudança social. Editora UnB, Brasília.

Fausto N eto A 1999. Comunicação e mídia impressa. Estudo sobre a Aids. Hacker Editores, São Paulo.

Foucault M 1996. A ordem do discurso. Edições Loyola, São Paulo.

Gomide PIC 1990. M enor infrator: a caminho de um novo tempo. Editora Juruá, Curitiba.

Gramsci A 1981 A concepção dialética da história. (4ạ ed.). Editora Civilização Brasileira, Rio de Janeiro.

Hobsbawn E 1995. A era dos extremos - o breve século XX. Companhia das Letras, São Paulo.
M artín-Barbero J 2001. D os meios às medições: comunicação, cultura e hegemonia. Editora U frj, Rio de Janeiro.

M cAlister A 2000. La violence juvenil en las Américas: estudios innovadores de investigación, diagnóstico y prevención. OPS, Washington.

M inayo M CS 1994. O desafio do conhecimento: pesquisa qualitativa em saúde. Editora Hucitec, São Paulo.

M inayo M CS \& Souza ER 1999. É possível prevenir a violência? Ciência \& Saúde Coletiva, 4(1):7-32.

M N M M R/I base/NEV-USP 1991. Vidas em risco: assassinatos de crianças e adolescentes no Brasil. M M M RIbase-NEV-USP, Rio de Janeiro.

Oriol R 2001. Información sobre drogas: acciones, valores, orientaciones, pp. 1-10 In D esafios da pós-modernidade: diversidade e perspectivas. Editora da U erj, Rio de Janeiro (no prelo).

Pêcheux M 1990. Semântica e discurso. Editora Unicamp, Campinas.

Pilotti F \& Rizzini I 1995. A arte de governar crianças: a história das políticas sociais, da legislação e da assistência à infância no Brasil. Instituto Interamericano del Niño-Editora da Universidade Santa ÚrsulaAmais Livraria e Editora, Rio de Janeiro.

Ramonet I 1996. Imprensa contra a corrente, p. 5. In Caderno I déias, Jornal do Brasil, 16/3/96.

Rebelo J 2000. 0 discurso do jornal. Editorial Notícias, Lisboa.

Sodré M 1992. O social irradiado: violência urbana, neogrotesco e mídia. Editora Cortez, São Paulo.

Souza ER; Assis SG \& Silva CM FP 1997. Violência no Município do Rio de Janeiro: áreas de risco e tendências da mortalidade entre adolescentes de 10 a 19 anos. Revista Pan-americana de Salud Pública, 1:389-398.

Veron E 1978. Le Hibou. Communication, n. 28.

Volpi M 1997. 0 adolescente e 0 ato infracional. Editora Cortez, São Paulo.

Wolf M 2001. Teorias da comunicação. Editorial Presença, Lisboa.

Artigo apresentado em 10/11/2001

Versão final apresentada em 13/3/2002

Aprovado em 8/4/2002 